\title{
THE STUDY OF MULTISTAGE GRINDING OF RYE
}

\section{Waleed HAMEED HASSOON ${ }^{1,2}$, Dariusz DZIKI ${ }^{2}$}

${ }^{1}$ College of Food Sciences, Department of Food Technology, University of Al-Qasim Green Babylon, IRAQ

${ }^{2}$ Thermal Engineering Department, University of Life Sciences, Lublin, POLAND

E-mail of the corresponding author: dariusz.dziki@up.lublin.pl

Keywords: rye, grinding machinery, energy requirements, sustainable agriculture

\begin{abstract}
The aim of the study was to propose the method of multistage grinding of rye grain. Investigations were carried out on rye cultivar (Secale Cereale) Bosmo, collected in the year 2016. The samples of rye were tempered to adjust moisture contents to: 10, 12, 14, 16, 18, and $20 \%$ (w.b.). The grinding process was carried out in three combinations: grains were ground by using the laboratory hammer mill, rye was ground using the laboratory roller mill and the grains were preliminary ground using hammer mill and in the second stage the roller mill was used. The particle size distribution was determined and the grinding energy indices were evaluated. The results showed that hammer mill grinding is more energy consuming than particle size reduction using a roller mill. Most importantly, the multistage grinding of rye (roller mill in the first stage) significantly reduced energy requirements for hammer mill grinding and caused the highest degree of fineness. This method is especially preferred for sustainable agriculture practices.
\end{abstract}

\section{INTRODUCTION}

Rye (Secale cereal L.) is an important crop in Eastern, Central and Northern Europe and a rich source of dietary fibre. It is an excellent raw material for healthy and tasty foods. (Johansson et al. 2017; Zieliński et al. 2008). Rye products have repeatedly been shown to induce lower postprandial insulin response, with or without a corresponding decrease in glucose response, compared with refined wheat bread (Johanssonet et al. 2017). Rye contains biologically active substances with antioxidant properties by acting as reducing agents, free radical-scavengers and through formation of complexes with metals (Afzal et al. 2013). The nutritional benefits of rye consumption include positive effects on digestion and decreased risk of heart disease, hypercholesterolemia, obesity, and non-insulin dependent diabetes, and rye also has a protective effect against cancer (Hansen et al. 2004).

The basic goals of sustainable agriculture are environmental health, economic profitability, and social and economic equity. The grinding process is the most important and the most energy consuming in processing of agricultural products. Thus the knowledge about the methods of grinding energy saving is in agreement with the goals of sustainable agriculture. The grinding energy depends both on the properties of the grinding material and on the used machines and their work parameters (Saiedirad et al. 2008). Particle size of ground grains has influence on properties of the flour (Dziki et al. 2014). Cereals grinding is mainly performed with the use of hammer mills and roller mills. The most commonly applied in practice are the roller mills. However they have little effect on bran size reduction. The hammer mills are more appropriate for grinding fiber-rich bran and germ and thus for whole grain flour production (Dziki and Laskowski 2010). Moreover, the knowledge of fracture characteristics of grains is imperative for a rational design of efficient grinding systems, as well as the optimization of the process and product parameters (Prabhasankar and Rao 2004). The objective of this study was to propose the method of multistage grinding of rye grain. Besides, the effect of grain moisture content on grinding energy requirements was studied. 


\section{MATERIAL AND METHODS}

Investigations were carried out on rye cultivar (Secale Cereale) Bosmo, collected in the year 2016. The samples of rye were tempered by adding water or by drying at $35{ }^{\circ} \mathrm{C}$ to adjust moisture contents to: 10, 12, 14, 16, and $18 \%$ (w.b.) and storing for $48 \mathrm{~h}$. The tempered grains were divided in three portions. The grinding process was carried out in three combinations:

- grains were ground by using the laboratory hammer mill POLYMIX-MicroHammermill MFC equipped with a $2.0 \mathrm{~mm}$ screen size (Dziki 2008),

- $\quad$ rye was ground using the laboratory roller mill SK (Dziki and Laskowski 2004),

- grains were preliminary ground using roller mill and in the second stage the hammer mill was used.

The amount of energy consumed during grinding was obtained by means of a power transducer, a data acquisition and a computer system that recorded the data measured by the transducer. The unloaded grinder current was monitored prior to grinding and remained constant over all testing and the grinding energy was calculated by using special computer software. The energy required to run the mill with no load was determined and subtracted from the total energy to obtain the grinding energy. The specific grinding energy was determined as the ratio of the grinding energy to the mass of the material taken for grinding. The sieving test was used to determine the particle size distribution of the pulverized material. Sieving was carried out for 5 min, by using a laboratory screen (Thyr 2, SASKIA, Germany), and separated into fractions using sieves of sizes: 1.600, 1.200, 0.800, 0.630, 0.400, 0.315 and $0.200 \mathrm{~mm}$. On the basis of the particle size distribution, the average particle size $(\mathrm{d} p)$ was calculated as follows (Velu et al. 2006). The grinding ability index $\left(E_{s}\right)$ was calculated as a ratio of the grinding energy to the surface area of the pulverized material. The surface area of the pulverized material was evaluated according to the procedure described by Jha and Sharma (2010). The Sokołowski's grinding index was calculated on the basis of the size reduction theory described by Sokołowski (1996). Details of the procedure used in determining these indices can be found in Dziki and Laskowski (2010) and Dziki (2011).

The measurements of crushing energy and grinding energy were replicated in triplicate. The obtained data was further subjected to a statistical analysis and the consequent evaluations were analyzed with the variance analysis using the Statistica 6.0 software (StatSoft, Inc., Tulsa, USA). Moreover, standard deviations were evaluated and the relations were described using the regression equations. The statistical differences between the treatment groups were estimated with Tukey test. All the statistical tests were carried out at the significance level of $\alpha=0.05$.

\section{RESULTS}

The sieve analysis of ground material showed that when roller mill was used for grinding the highest amount of coarse particles (above $1.6 \mathrm{~mm}$ ) was obtained. When hammer mill was used for grinding alone or as a preliminary step before roller mill grinding the fraction of particles above $1.6 \mathrm{~mm}$ was not found in the ground rye. From the other hand, the highest mass fraction of fine particles (below $0.2 \mathrm{~mm}$ ) was observed when two kinds of mills were 
used both (Table 1). When roller mill was used for grinding an increase the grain moisture content caused an increase of the mass fraction of coarse particles and the highest mass fraction of fine particles was obtained when rye moisture was $14 \%$. Interestingly this tendency was also found when roller mill and hammer mill were used together. In the case of hammer mill the highest mass fraction of these particles was found when grain moisture was $14 \%$. The average particle size $(d)$ of ground rye obtained from different methods of mill was presented on Fig. 1.

Table 1. Particle size distribution of ground material

\begin{tabular}{|c|c|c|c|c|c|c|}
\hline \multirow{2}{*}{$\begin{array}{l}\text { Range of class } \\
(\mathrm{mm})\end{array}$} & \multirow[t]{2}{*}{ Used mill } & \multicolumn{5}{|c|}{ Grain moisture (\%) } \\
\hline & & 10 & 12 & 14 & 16 & 18 \\
\hline$>1.6$ & \multirow{8}{*}{ hammer mill } & $0 \pm 0.00$ & $0 \pm 0.00$ & $0 \pm 0.00$ & $0 \pm 0.00$ & $0 \pm 0.00$ \\
\hline $1.2-1.6$ & & $6.7 \pm 0.22$ & $5.1 \pm 0.16$ & $6.2 \pm 0.24$ & $5.5 \pm 0.15$ & $5.4 \pm 0.11$ \\
\hline $0.8-1.2$ & & $15.6 \pm 0.18$ & $15.5 \pm 0.08$ & $16.0 \pm 0.31$ & $15.5 \pm 0.19$ & $15.2 \pm 0.17$ \\
\hline $0.63-0.8$ & & $23.1 \pm 0.31$ & $23.2 \pm 0.38$ & $24.4 \pm 0.45$ & $22.8 \pm 0.39$ & $24.02 \pm 0.42$ \\
\hline $0.4-0.63$ & & $20.69 \pm 0.00$ & $21.01 \pm 0.00$ & $21.54 \pm 0.00$ & $21.8 \pm 0.00$ & $23.26 \pm 0.00$ \\
\hline $0.315-0.4$ & & $6.07 \pm 0.00$ & $5.92 \pm 0.00$ & $5.8 \pm 0.00$ & $6.55 \pm 0.00$ & $7.63 \pm 0.00$ \\
\hline $0.2-0.315$ & & $13.08 \pm 0.00$ & $13.45 \pm 0.00$ & $10.75 \pm 0.00$ & $13.54 \pm 0.00$ & $12.29 \pm 0.00$ \\
\hline$<0.2$ & & $14.87 \pm 0.00$ & $15.89 \pm 0.00$ & $15.2 \pm 0.00$ & $14.3 \pm 0.00$ & $12.22 \pm 0.00$ \\
\hline$>1.6$ & \multirow{8}{*}{ roller mill } & $0.2 \pm 0.01$ & $0.9 \pm 0.03$ & $0.9 \pm 0.04$ & $7.0 \pm 0.38$ & $16 \pm 0.62$ \\
\hline $1.2-1.6$ & & $9.0 \pm 0.23$ & $18.6 \pm 0.41$ & $19.4 \pm 0.52$ & $28.4 \pm 0.74$ & $28.3 \pm 0.35$ \\
\hline $0.8-1.2$ & & $9.8 \pm 0.26$ & $10.5 \pm 0.35$ & $11.0 \pm 0.27$ & $9.4 \pm 0.55$ & $8.3 \pm 0.18$ \\
\hline $0.63-0.8$ & & $17.3 \pm 0.28$ & $13.7 \pm 0.31$ & $11.3 \pm 0.14$ & $11.1 \pm 0.12$ & $9.7 \pm 0.21$ \\
\hline $0.4-0.63$ & & $37.0 \pm 0.56$ & $28.1 \pm 0.42$ & $29.7 \pm 0.51$ & $19.3 \pm 0.33$ & $15.1 \pm 0.17$ \\
\hline $0.315-0.4$ & & $7.6 \pm 0.14$ & $7.3 \pm 0.18$ & $6.1 \pm 0.07$ & $5.0 \pm 0.11$ & $4.7 \pm 0.15$ \\
\hline $0.2-0.315$ & & $7.8 \pm 0.08$ & $7.7 \pm 0.19$ & $6.6 \pm 0.14$ & $6.7 \pm 0.23$ & $6.0 \pm 0.14$ \\
\hline$<0.2$ & & $11.4 \pm 0.63$ & $13.5 \pm 0.54$ & $14.9 \pm 0.62$ & $13.1 \pm 0.23$ & $12.0 \pm 0.32$ \\
\hline$>1.6$ & \multirow{8}{*}{$\begin{array}{l}\text { roller mill and } \\
\text { hammer mill }\end{array}$} & $0 \pm 0.00$ & $0 \pm 0.00$ & $0 \pm 0.00$ & $0 \pm 0.00$ & $0 \pm 0.00$ \\
\hline $1.2-1.6$ & & $0.3 \pm 0.05$ & $0.8 \pm 0.06$ & $1.0 \pm 0.07$ & $1.9 \pm 0.08$ & $3.9 \pm 0.17$ \\
\hline $0.8-1.2$ & & $1.4 \pm 0.12$ & $3.4 \pm 0.11$ & $4.8 \pm 0.21$ & $4.9 \pm 0.31$ & $6.4 \pm 0.29$ \\
\hline $0.63-0.8$ & & $7.0 \pm 0.21$ & $10.7 \pm 0.36$ & $11.7 \pm 0.32$ & $13.0 \pm 0.35$ & $14.0 \pm 0.42$ \\
\hline $0.4-0.63$ & & $45.5 \pm 0.57$ & $38.8 \pm 0.62$ & $37.4 \pm 0.66$ & $28.5 \pm 0.54$ & $26.0 \pm 0.72$ \\
\hline $0.315-0.4$ & & $16.8 \pm 0.39$ & $15.2 \pm 0.35$ & $12.2 \pm 0.26$ & $12.0 \pm 0.37$ & $11.4 \pm 0.28$ \\
\hline $0.2-0.315$ & & $15.0 \pm 0.73$ & $13.6 \pm 0.52$ & $10.3 \pm 0.18$ & $19.6 \pm 0.48$ & $20.5 \pm 0.39$ \\
\hline$<0.2$ & & $14.0 \pm 0.58$ & $17.6 \pm 0.56$ & $22.7 \pm 0.73$ & $20.2 \pm 0.61$ & $17.8 \pm 0.65$ \\
\hline
\end{tabular}

The results showed linear relation between the average particle size and grain moisture. As the moisture of rye increased the particle size also increased. This tendency was found for each grinding method. Interestingly when the moisture of grain was $10 \%$ the similar values of average particle size was obtained after grinding rye by using hammer mill and roller mill. At the higher moisture content the highest values of average particle size were obtained when roller mill was used. When the two mills were combined into one grinding system the lowest values of particle size were obtained. 

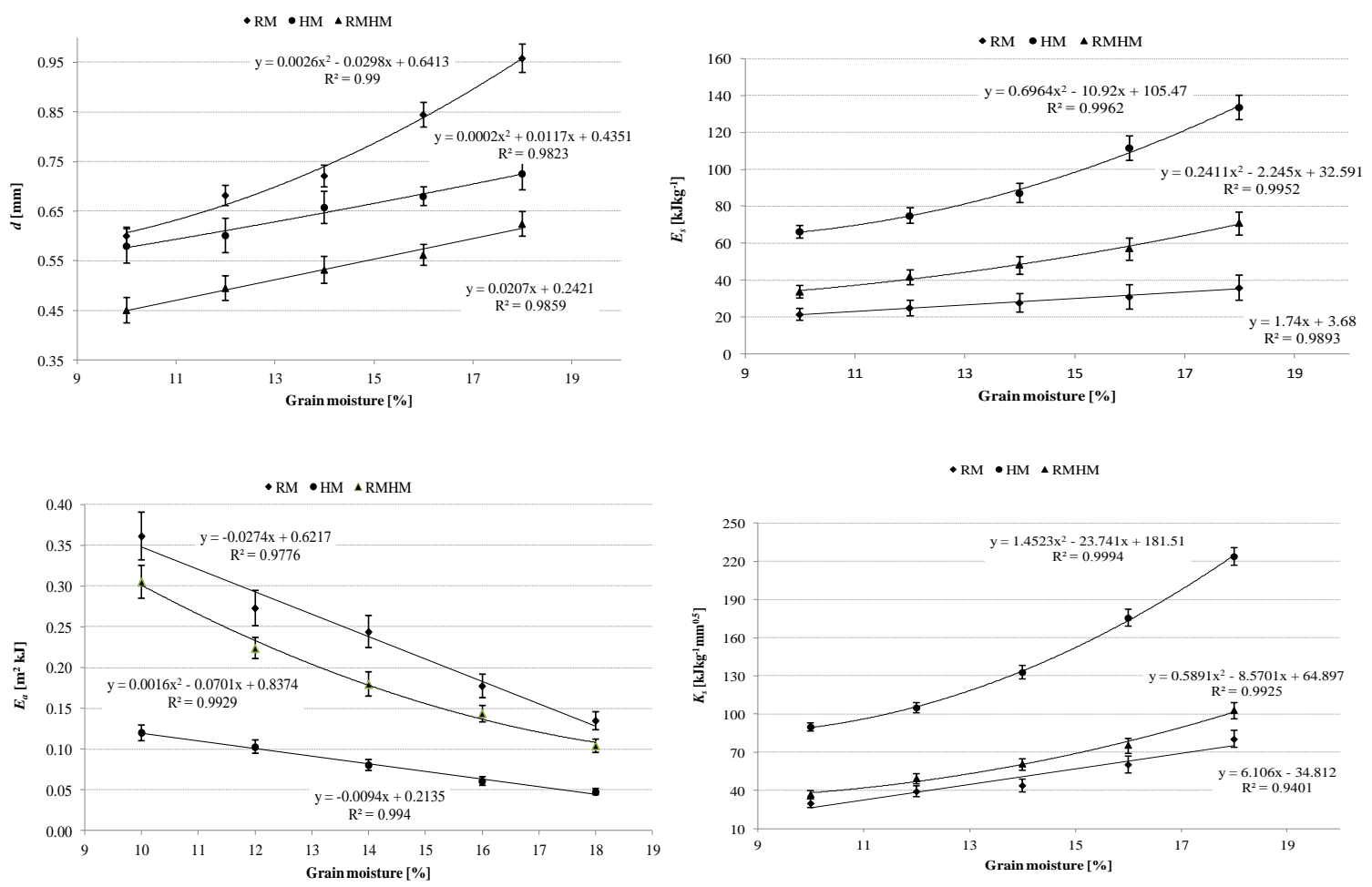

Fig. 1. Influence of moisture content and the method of grinding on average particle size $(d)$, specific grinding energy $\left(E_{s}\right)$, grinding ability index $\left(E_{\mathrm{a}}\right)$ and Sokołowski’s grinding index $\left(K_{s}\right)$; RM- roller mill, HM - hammer mill, RMHM - roller mill and hammer mill

The obtained data showed that there is a significant influence of grain moisture and method of grinding on specific grinding energy. The highest values of specific grinding energy were found when hammer mill was used for particle size reduction, whereas the lowest values of this parameter were obtained when hammer mill was used. An increase of grain moisture content from $10 \%$ to $18 \%$ caused an increase of specific grinding energy from 21.3 to $35.7 \mathrm{~kJ} \cdot \mathrm{kg}^{-1}$, from 66.2 to $133.6 \mathrm{~kJ} \cdot \mathrm{kg}^{-1}$ for roller mill and hammer mill and from, respectively. When roller mil was used as the preliminary step before hammer mill grinding the specific grinding energy ranged from 33.6 to $70.9 \mathrm{~kJ}^{\circ} \mathrm{kg}^{-1}$ (Fig. 1). The grinding ability index and Solołowski's grinding index are the important indices describing the grinding process because this indices take into account the particle size distribution of ground material. These indices also confirmed that the multistage grinding of rye significantly reduced energy requirements for hammer mill grinding.

\section{CONCLUSIONS}

The results clearly showed that hammer mill grinding is more energy consuming than particle size reduction using a roller mill. The specific grinding and grinding ability index were several times higher when hammer mill was used. Besides, the increase of grain moisture content caused an increase of specific grinding energy. However this effect was stronger and non-linear when hammer mill was used for grinding. Most importantly, the multistage grinding of rye (roller mill in the first stage) significantly reduced energy requirements for hammer mill grinding. Besides, the particle size distribution strongly depended on the 
methods of grinding and grain moisture. The highest mass fraction of fine particles (below $0.2 \mathrm{~mm}$ ) was observed when two kinds of mills were connected in multistage grinding process. When roller mill was used for grinding alone an increase the grain moisture content caused an increase of the mass fraction of coarse particles and the highest mass fraction of fine particles was obtained when rye moisture was $14 \%$. Interestingly, this tendency was also found when roller mill and hammer mill were used together. In the case of hammer mill the highest mass fraction of fine particles was found when grain moisture was $14 \%$. Moreover, the multistage grinding caused the highest degree of fineness. The proposed integrated method of grinding is especially preferred for sustainable agriculture practices.

\section{REFERNCES}

Afzal, S., Shehzad, A., Randhawa, M. A., Asghar, A., Shoaib, M., \& Jahangir, M. A. (2013). Health benefits and importance of utilizing wheat and rye. Pak J Food Sci, 23(4), 212-222.

Dziki D., \& Laskowski J. (2004). The energy-consuming indexes of wheat kernel grinding process. TEKA Commission of Motorization and Power Industry in Agriculture, IV, 62-69.

Dziki, D. (2011). Effect of preliminary grinding of the wheat grain on the pulverizing process. Journal of food engineering, 104(4), 585-591.

Dziki, D., \& Laskowski, J. (2010). Study to analyze the influence of sprouting of the wheat grain on the grinding process. Journal of Food Engineering, 96(4), 562-567.

Hansen, H. B., Møller, B., Andersen, S. B., Jørgensen, J. R., \& Hansen, Å. (2004). Grain characteristics, chemical composition, and functional properties of rye (Secale cereale L.) as influenced by genotype and harvest year. Journal of agricultural and food chemistry, 52(8), 2282-2291.

Jha, S. N., \& Sharma, R. (2010). Physical, gravimetric and functional characterization of various milling fractions of popped gorgon nut (Euryale ferox). Journal of food science and technology, 47(5), 564-570.

Johansson, D. P., Gutiérrez, J. L. V., Landberg, R., Alminger, M., \& Langton, M. (2017). Impact of food processing on rye product properties and their in vitro digestion. European Journal of Nutrition, 1-16.

Prabhasankar P, Rao PH. (2004) Effect of different milling methods on chemical composition of whole wheat flour. Eur Food Res Technol. 213, 465-469.

Saiedirad, M. H., Tabatabaeefar, A., Borghei, A., Mirsalehi, M., Badii, F., \& Varnamkhasti, M. G. (2008). Effects of moisture content, seed size, loading rate and seed orientation on force and energy required for fracturing cumin seed (Cuminum cyminum L.) under quasi-static loading. Journal of Food Engineering, 86(4), 565-572.

Sokołowski, M. (1996). Energy consumed in grinding-a new idea of a general law of comminution-new tests stands and testing results. Récents Progress en Génie Procédés, 10, 221-226.

Velu, V., Nagender, A., Rao, P. P., \& Rao, D. G. (2006). Dry milling characteristics of microwave dried maize grains (Zea mays L.). Journal of Food Engineering, 74(1), 30-36.

Zieliński, H., Michalska, A., Ceglińska, A., \& Lamparski, G. (2008). Antioxidant properties and sensory quality of traditional rye bread as affected by the incorporation of flour with different extraction rates in the formulation. European Food Research and Technology, 226(4), 671-680. 